the priorities are to restore adequate ventilation and obtain a pathological diagnosis. ${ }^{1}$

The choice of bronchoscopic techniques includes NdYAG laser, diathermy and cryotherapy, ${ }^{2}$ all of which carry a risk of bleeding. Thereafter, complete resection with primary reconstruction of the airways offers the best chance of cure. Anaesthesia presents special difficulties in these cases. High-frequency jet ventilation can be a useful adjunct. In our patient the ventilatory difficulties were unsurmountable and cardiopulmonary bypass was necessary.

The stricture that developed postoperatively, caused by fibrosis of the pericardial patch, is a well documented complication. Laser and balloon dilatation offer immediate relief, but in cases of recurrence an endobronchial stent can provide good function in the long term.

In the UK, most tracheal and carinal surgery is undertaken in a few specialized centres and, even in these,

\section{Retroperitoneal fibrosis mimicking prostate cancer}

\section{Shabbir ${ }^{1} \quad J$ S Gelister ${ }^{2}$}

J R Soc Med 2006;99:39-40

Retroperitoneal fibrosis typically affects the region extending from the second lumbar vertebra to the pelvic brim. Where it extends below the pelvic brim, encasement of individual pelvic organs can mimic malignant disease. ${ }^{1,2}$

\section{CASE HISTORY}

A previously fit and well retired carpenter aged 65 was investigated after reporting painless macroscopic haematuria of short duration. The only noteworthy physical finding was a firm irregular prostate clinically compatible with a T3/T4 malignant lesion. Abdominal ultrasound showed moderate to gross bilateral hydronephrosis. CT confirmed the hydronephrosis and the irregularity of the prostate (Figure 1); in addition, $\mathrm{CT}$ and chest radiographs revealed extensive bilateral calcified pleural plaques typical of asbestos exposure. Prostate specific antigen was normal $(1.5 \mathrm{ng} /$ $\mathrm{mL}$ ); serum creatinine was raised at $172 \mu \mathrm{mol} / \mathrm{L}$ and the erythrocyte sedimentation rate (ESR) was $56 \mathrm{~mm} / \mathrm{h}$.

${ }^{1}$ Department of Urology, St George's Hospital, London SW17 ORE; ${ }^{2}$ Barnet General Hospital, London, UK

Correspondence to: M Shabbir

E-mail: majidshabbir@hotmail.com the large majority of resectional procedures are done electively, in a controlled environment. However, any cardiothoracic centre may find itself confronted with one of these emergencies; and if transfer is too dangerous to the patient, the local surgeons may have to rely on basic principles and their trade craft. In the instance described here, they were much helped by the availability of cardiopulmonary bypass.

\section{REFERENCES}

1 Venuta F, Rendina EA, De Giacomo T, et al. Nd:YAG laser resection of lung cancer invading the airway as a bridge to surgery and palliative treatment. Ann Thorac Surg 2002;74:995-8

2 Daddi G, Puma F, Avenia N, et al. Resection with curative intent after endoscopic treatment of airway obstruction. Ann Thorac Surg 1998;65:203-7

3 Burns KE, Orons PD, Dauber JH, et al. Endobronchial metallic stent placement for airway complications after lung transplantationlongitudinal results. Ann Thorac Surg 2002;74:1934 41

On examination under anaesthesia a distinct pelvic mass was felt at the level of the bladder base; the bladder was cystoscopically normal. Retrograde imaging showed bilateral tapering strictures of the distal ureters suggestive of external compression. Ureteric stents were inserted on both sides. Biopsies from the pelvic lesion contained dense fibrous tissue compatible with retroperitoneal fibrosis; no evidence of malignant disease was found in the pelvic mass or the prostate. Cancer having been excluded, the patient was started on prednisolone. Four and eight months later, retrograde studies showed only marginal improvement in the ureteric obstruction despite a fall in the ESR to

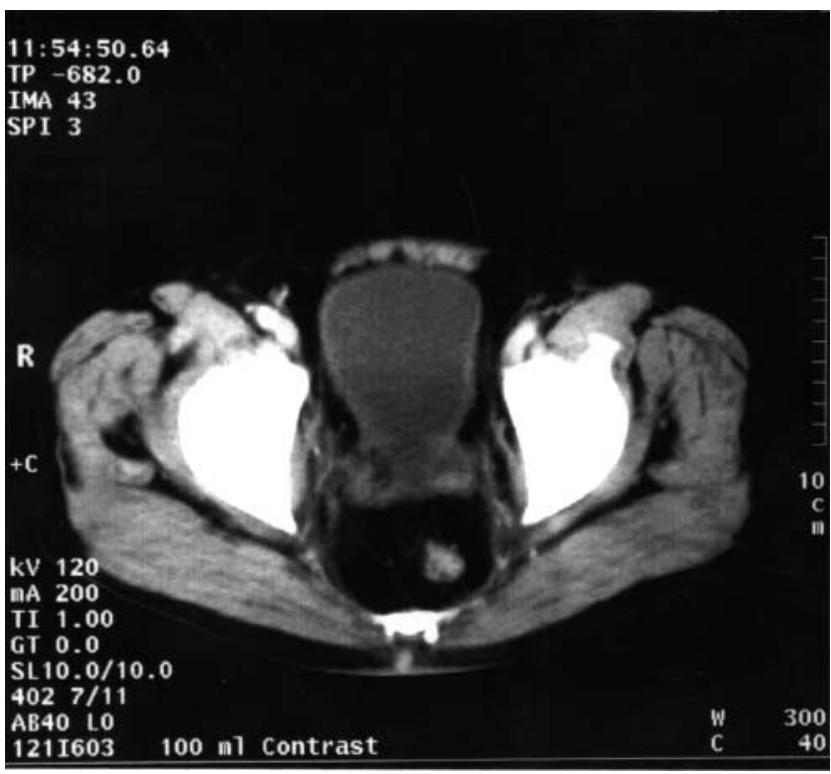

Figure 1 CT of pelvis 
$9 \mathrm{~mm} / \mathrm{h}$. Ureterolysis and ureteric reimplantation was planned, but had to be delayed when the patient had a major myocardial infarction.

\section{COMMENT}

Asbestos bodies have also been reported in various retroperitoneal organs, including the kidney and adrenal glands, ${ }^{3}$ and two previous case studies have reported a link between asbestos exposure and retroperitoneal fibrosis. ${ }^{4,5}$ Uiba et $a 1 .{ }^{6}$ found that patients with significant asbestos exposure ( $>10$ fibre-years) were at nine-fold excess risk with a mean latency period from first exposure of 30-33 years. ${ }^{6}$ Our patient had worked as a carpenter and ceramic tiler all his life, and the likely cause of his disease was occupational exposure to asbestos.

Isolated retroperitoneal fibrosis within the true pelvis is very rare, and involvement of single organs presents special diagnostic challenges. Symptoms can range from dyspareunia, when the cervix is affected ${ }^{2}$ to a change in bowel habit with rectal involvement. ${ }^{1}$ The features can resemble those of malignant disease both clinically and radiologically. We have not found a previous case in which retroperitoneal fibrosis gave the appearance of prostate cancer.
Once a malignancy is excluded, the aim of treatment is to restore normal renal function by relief of obstructive uropathy. Primary treatment with steroid therapy and ureteric stenting has been shown to be effective in most patients. $^{7}$ Failure of medical therapy necessitates open ureterolysis.

\section{REFERENCES}

1 Haciyanli M, Erkan N, Elverdi B, et al. Retroperitoneal fibrosis mimicking a rectal tumour: report of a case. Dis Colon Rectum 1998;41:664-6

2 Kurzel RB, Yoonesi M, Munabi A. Retroperitoneal fibrosis: a two decade experience and gynaecologic manifestations. Int J Gynaecol Obstet 1981;19:271-80

3 Auerbach O, Constan AS, Garfinkel L, et al. Presence of asbestos bodies in organs other than the lung. Chest 1980;77:133-7

4 Buolard JC, Hanslik T, Moulonguet Doleris L, Prinseau J, Baglin A. Asbestos and idiopathic retroperitoneal fibrosis. Lancet 1995;345:1379

5 Maguire GP, Meggs LG, Addonizio J, Del Guerico LRM. Association of asbestos exposure, retroperitoneal fibrosis and acute renal failure. NY St J Med 1991;91:357-9

6 Uiba T, Oksa P, Auvinen A, et al. Asbestos exposure as a risk factor for retroperitoneal fibrosis. Lancet 2004;363:1422-6

7 Kardar AH, Kattan S, Lindstedt E, Hanash K. Steroid therapy for idiopathic retroperitoneal fibrosis: dose and duration. J Urol 2002; 168:550-5

\section{Thirty years on quinidine for paroxysmal ventricular tachycardia}

\author{
Arthur Hollman
}

J R Soc Med 2006;99:40-41

Quinidine is no longer widely used for the termination and prevention of arrhythmias because of concern about cardiac and systemic side-effects. This concern was not shared by the patient reported here, who took the drug continuously for 30 years.

\section{CASE HISTORY}

The patient had experienced missed beats since the age of 25 , but at age 51 he developed episodes of paroxysmal ventricular tachycardia. The electrocardiogram showed that the arrhythmia originated in the right ventricular outflow tract, QT interval $0.43 \mathrm{~ms}$ (Figure 1). Physical examination

Sea Bank, Chick Hill, Pett TN3 4EQ, UK

E-mail: arthur@hollman.co.uk revealed a late systolic click at the apex. Chest X-ray and echocardiogram were normal. Procaine amide and practolol had failed to give control and I started him on quinidine sulphate, in the form of Kinidin Durules (Astra), $2 \mathrm{~g}$ per day. Blood levels were satisfactory at $2.0-2.3 \mathrm{mg} / \mathrm{dL}$; the QT interval increased to $0.47 \mathrm{~ms}$. He continued to have extrasystoles and short runs of tachycardia but usually these were well tolerated. Addition of propranolol and then mexiletine did not give improvement and the patient felt better on quinidine alone. He continued to live a very active life as a horticulturist. At age 78 amiodarone was substituted but he felt less well on this and asked for the quinidine to be reinstated. The following year he developed biventricular failure, for which he was prescribed celiprolol, losartan and furosemide; he insisted on continuing the quinidine. At age 83 he was experiencing infrequent episodes of ventricular extrasystoles and tachycardia, and he died after an operation for colon cancer.

\section{COMMENT}

Quinidine was promoted by Thomas Lewis for the termination and prevention of atrial fibrillation, ${ }^{1}$ after Karel Wenckebach had shown in 1914 that the related drug quinine could halt paroxysms of this arrhythmia. ${ }^{2}$ In 1951 Maurice Sokolow reported conversion to normal rhythm with no important side-effects in $80 \%$ of 111 personal cases of atrial fibrillation and flutter, using blood level control. 